\title{
Towards a Governance Model for a Biosphere Mega Reserve in South Africa
}

\author{
Peter B. Myles* \\ IUCN Tourism \& Protected Areas Specialist Group, IUCN World Commission on Protected Areas, Global \\ Sustainable Tourism Council, International Coastal \& Marine Tourism Society, South Africa

\begin{abstract}
*Corresponding Author: Peter B. Myles, IUCN Tourism \& Protected Areas Specialist Group, IUCN World Commission on Protected Areas, Global Sustainable Tourism Council, International Coastal \& Marine Tourism Society, South Africa
\end{abstract}

\begin{abstract}
Currently there is healthy global discussion and debate on what kind of governance is required to sustain protected areas in the future. There are some who believe the notion of "stakeholders" is no longer appropriate for protected area management. The idea of "constituencies" has been suggested as a much more descriptive, and broader, identification of those impacted by decisions and thus would include not only citizens but visitors and others who benefit from the values and heritage provided by protected areas. Sustainable development cannot be achieved without the appropriate means and mechanisms for empowering and involving the stakeholders and partners, and for holding them responsible. Furthermore, there is evidence that this interrelation requires a new understanding of planning ("extreme planning"). Jungmeier (2011) draws the conclusion in his paper on Third Generation Protected Areas that protected areas, stringently put into the context of sustainable development, form a "third generation" of protected areas. The most important and distinctive elements of this new generation are the new mechanisms of steering and governing, an increasing number of scientific disciplines and a new understanding of the socio-sphere in the eco-sphere. A socio-sphere is comprised of individuals with very different lifestyles and social networks living in close proximity without untoward interference with each other. An eco-sphere is the volume of area where biological matter can exist. Management of protected areas has increased in complexity and thus requires particular personal and technical competencies (Jungmeier 2011). The growth and transformation of the 210,000 ha Baviaanskloof World Heritage Site, which incorporates a Nature Reserve and Wilderness Area, to exciting expansion plans for the development of a 500,000 ha mega-reserve, has been observed by the author over a period of twenty four years between 1988 and 2012. The author concludes with his recommendations on the most appropriate form of governance for the proposed Baviaanskloof Mega-Reserve Landscape Initiative (BMR) based on these observations.
\end{abstract}

Keywords: Baviaans Mega-Reserve, Biodiversity Conservation, World Heritage Site, Cluster, Biosphere, Protected Areas Governance, Third Generation Protected Areas.

\section{INTRODUCTION}

The terms constituents, stakeholders, and communities often mean different things to different people. For the purpose of this article, the terms used are those defined in the article, 'From Constituents to Stakeholders: Community-Based approached to Building Organizational Ownership and Providing Opportunities to Lead' published by the Research Centre for Leadership in Action (undated). These terms are defined as follows:

\subsection{Constituents}

Constituents are the people an organization serves, advocates for, or organizes. This includes those who share a geographic community or interest area and who directly benefit from the organization's work. So, for example, constituents may also include those whom the organization could potentially serve or "recruit," to use the language of organizing and membership-based groups. Organizations generally understand constituency in multiple ways that may even evolve and change during the life of the organization. Some work on the basis of accountability: the constituents are those whom the organization must answer to for its use of resources and in evaluating its effectiveness. Some define their constituents as other organized groups, not just individuals, such as unions as well as workers. 
Others think of their constituents both as the people they directly engage in their programs, such as teachers, as well as those whose lives they ultimately hope to improve, such as children.

\subsection{Stakeholders}

Stakeholders are the individuals who care about an organization and consider it their own. They devote time or resources to ensure the internal development of an organization and/or its impact in the community. Internal development includes fundraising, financial management, human resources, and program oversight.

Community impact includes aligning new program development with the organization's mission. It also includes the ability to meet needs in a service organization, build the power of grassroots leaders in an organizing group, or enable constituents to publicly represent the organization and its issues.

\subsection{Communities}

Communities are groups of people who share an area of interest and/or a geographic area. Common areas of interest include social or economic conditions, health status, race, ethnicity, or gender. Geographic areas include neighborhoods, cities, or regions.

\subsection{Challenges of Protected Areas Governance}

There is increasing pressure on the commercialization of protected areas to make them more viable and yet very few protected area managers appear to have received formal training on the basics of business management. Concessions are offered without identifying target markets. Ideally target markets should determine what kind of accommodation and activities would appeal to wildlife tourists, nature tourists, experiential tourists, adventure tourists and geo-tourists to name just a few. However, these niche markets are often lumped together and classified as 'ecotourism' even though research has clearly indicated that visitor profiles are different. In many cases what tourists actually expect from a visit to a protected area can vary quite considerably. The Baviaanskloof Mega-Reserve Landscape Initiative (BMR) has as its core the Baviaanskloof World Heritage Site, an ongoing project rather than a fully bordered reserve area. It is one of the eight protected areas that make up the Cape Floral Region Protected Areas listed as a World Heritage Site. The BMR is home to over 1000 different plant species and encompasses many different geological characteristics, landscapes and seven fully distinguishable biomes. Much of its landscape is rugged and mountainous, and this along with the floral and biome diversity has created an environment that also supports a great diversity of mammal and bird species.

The vision of the BMR is to expand and consolidate the existing protected area and create a megareserve in which the conservation of the regions biodiversity and natural resources is aligned with rural and agricultural development needs. This involves protecting existing wilderness and wildlife areas while opening up borders between provincial, state and privately owned land to create 'biodiversity corridors' that allow the natural movement of wildlife. The envisaged mega reserve will therefore comprise a cluster of state-owned protected areas within a network of private and communal land with an eventual size of around 500,000 hectares. Private landowners who volunteer to become part of the mega-reserve will align their land-use activities with the principles and practices of biodiversity conservation.

To guide this initiative, a Conservation Strategy has been prepared based on a set of principles and underpinned by a vision and specific set of objectives. The mega-reserve project is planned to operate in a collaborative and coordinated manner with all stakeholders, and to achieve full integration with other local and regional planning and development initiatives. For the project's vision and objectives to be achieved, an individual and collective sense of pride in and ownership of the area, and a strong commitment by all stakeholders to act in its best interests, are required and good progress has been made in this regard. The author's research study is an assessment of the most appropriate form of governance for a diverse conservation estate. This included an evaluation of the management options such as a cluster of protected areas compared to a biosphere.

A cluster is defined as a geographic concentration of inter-connected companies and institutions working in a common industry e.g. protected areas and product owners working in the nature tourism industry. In addition, clusters encompass an array of collaborating and competing services and providers which create a specialized infrastructure that supports the cluster's industry. The study will 
suggest that a biosphere is a better and more appropriate mechanism for encouraging cooperation within a conservation domain (Nordin, 2003).

By design, there is no single model for governing biosphere reserves, but there are two common underlying principles: the management system of a biosphere reserve needs to be open, not closed, to community concerns; and it needs to be adaptable to changes in local circumstances. Biosphere reserves are meant to be places where communities can work in concert with the area's land-managing agencies, local governments, schools, and other institutions to design responses to external political, economic, and social pressures that affect the ecological and cultural values of the area. Each biosphere reserve has its own system of governance to ensure that it meets its functions and objectives.

\section{THE STUdy AREA}

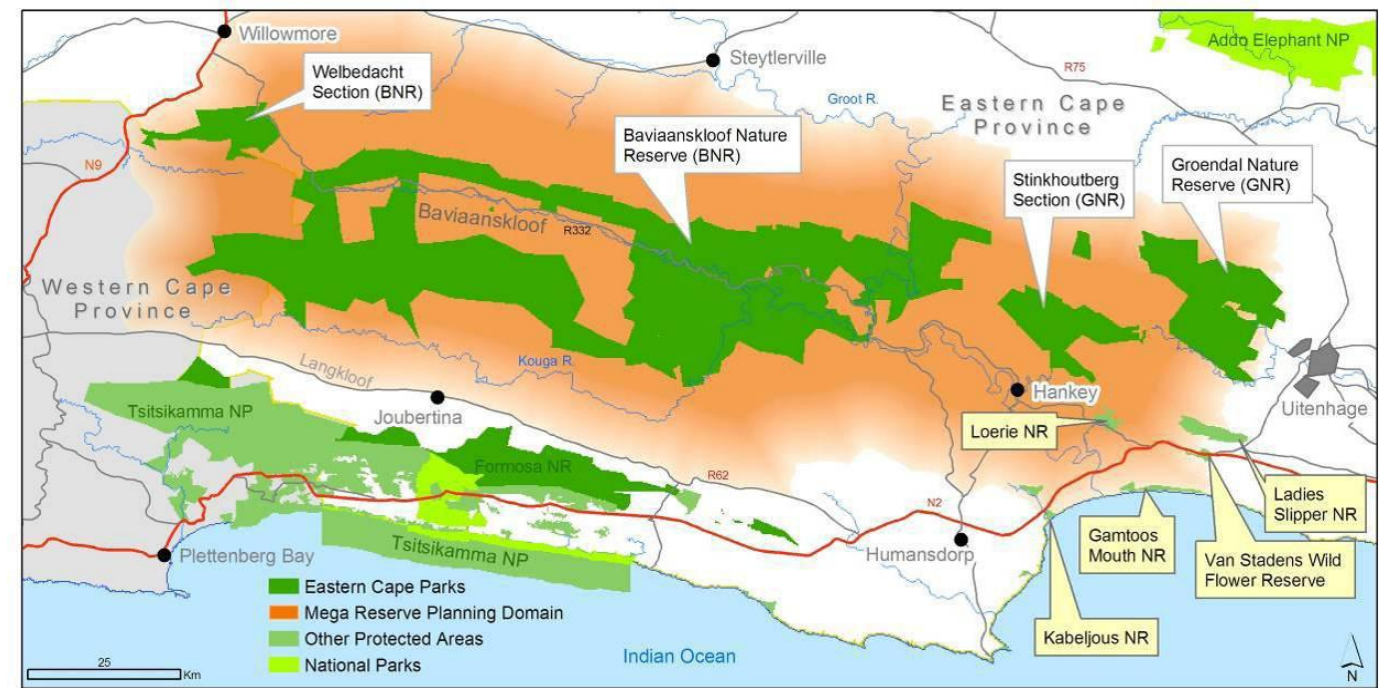

(Map showing the formal protected areas in the region, Skowno, 2007)

The Baviaanskloof - "Valley of Baboons" - lies between the parallel east-west running Baviaanskloof and Kouga mountain ranges in the western region of South Africa's Eastern Cape Province. The eastern-most point of the valley is some $95 \mathrm{~km} \mathrm{NW}$ of the coastal city of Port Elizabeth. The Baviaanskloof area includes a cluster of formal protected areas managed by the Eastern Cape Parks \& Tourism Agency (formerly Eastern Cape Park Board), of which the most well-known is the 210,000 ha Baviaanskloof Nature Reserve (BNR) - the third largest protected area in South Africa.

Land not incorporated in the BNR is used almost exclusively for stock farming (BMR Concept Document, 2005). The World Heritage Site has greater conservation importance and the highest conservation status. Irrigated crops are produced alongside some of the major rivers, most notably the Gamtoos River. The area is one of outstanding natural beauty, owing to its spectacular land forms, clad in a diverse array of plants and inhabited by a large variety of animals. This rich biodiversity, which has been internationally recognized by the awarding of prestigious World Heritage Site status to the BNR in 2004, along with seven other reserves in the Cape Floristic Region, provides several opportunities for local and regional economic development through activities such as nature-based tourism.

The area, which also contains a remarkable variety of pre-historical and historical sites, fulfils a critically important role as a water catchment zone, to supplement the growing water needs of the agricultural sector and urban growth in downstream areas to the east and south-east (BMR Concept Document, 2005). There are, however, several pressures that need to be addressed if the full potential of the area to achieve biodiversity conservation, maximum provision of water, and improvement of rural livelihoods is to be realized. These pressures derive from a range of environmental, institutional and socio-economic issues. The envisaged mega-reserve will comprise a cluster of state-owned protected areas within a network of private and communal land, with an eventual size of around 500,000 ha.

Private landowners who volunteer to become part of the mega-reserve will align their land-use activities with the principles and practices of biodiversity conservation. To guide this initiative, a 
Conservation Strategy, based on a set of principles and underpinned by a vision and specific set of objectives, has been compiled. The mega-reserve project is planned to operate in a collaborative and coordinated manner with all stakeholders, and to achieve full integration with other local and regional planning and development initiatives. An extensive Stakeholder Engagement Program has already achieved a high level of support for the project.

For the project's vision and objectives to be achieved, an individual and collective sense of pride in and ownership of the area, and a strong commitment by all stakeholders to act in its best interests, are required and good progress has been made in this regard. The Eastern Cape Parks \& Tourism Agency (ECPTA) Biodiversity Stewardship Program is addressing land owner participation through various levels of agreement. Increased awareness about the Baviaanskloof World Heritage Site, in particular, has catalyzed the growth of nature-based tourism activities on private land and in nearby towns. Since 2002, some 30,000 ha of land has been purchased for the formal protected area estate and over 50,000 ha, represented by 10 private initiatives, is being considered for inclusion under a variety of agreements and contracts.

Farmers in the western kloof area have recently set up a 45,000 ha conservancy on private owned land and are in discussions to initiate a stewardship contract. Major success has been achieved in the removal of invasive alien plants from a large part of the mega-reserve area, thereby promoting water catchment functioning. An innovative subtropical thicket restoration pilot project, which includes a component dealing with storage of atmospheric carbon and its role in mitigating the impact of global warming, is underway. Progress is being made with implementation actions related to reserve management and tourism development (BMR Concept Document, 2005).

To date, the Baviaanskloof Mega-Reserve Project has been successful in attracting R35.6 million to the area and has facilitated the employment of 200 people, a figure set to increase in the future. Other conservation-related projects have also attracted substantial funding - for example, the Working for Water project (R43 million over 10 years; 600 people employed annually) and the Working for Woodlands project (R3.6 million over three years; 55 people employed annually). In addition, the Baviaanskloof Reserve Cluster (annual management budget of R4.7 million), and special development projects with associated job creation (R10 million over five years), are making noteworthy contributions to the mega-reserve initiative (BMR Concept Document, 2005).

Notwithstanding good progress in the establishment of the BMR, much work and many challenges lie ahead. An overarching requirement is the need to secure large-scale funding to expand and maintain fully resourced provincial conservation agencies that can manage, monitor and evaluate the project, on both formal protected areas and on adjacent private or communal land. This will also contribute significantly to maintaining the integrity of the Baviaanskloof WHS in the future. It is now imperative that government, at the national and provincial levels, gives expression to its prioritization and institutionalization of support for the mega-reserve project. In this regard, it is encouraging that the Premier of the Eastern Cape and the responsible Member of the Executive Council have both endorsed the project as a flagship conservation and development initiative in the province.

The Baviaanskloof Mega-Reserve Project offers a unique and exciting opportunity to make a significant and lasting contribution to the conservation of globally important biodiversity, and to local economic development, with accompanying social upliftment (BMR Concept Document 2005).

\subsection{Vision for the Baviaanskloof Mega-Reserve}

The Baviaanskloof region is one of three priority areas in the Cape Floristic Region (CFR) that have been identified by the Cape Action for People and the Environment (C.A.P.E) as suitable for the establishment of so-called mega-reserves, which is a conservation landscape greater then 400,000 ha in extent. The vision of the Baviaanskloof Mega-reserve Project is to expand and consolidate the existing protected area and create a mega-reserve in which the conservation of the regions biodiversity and natural resources is aligned with rural and agricultural development needs (Eastern Cape Parks Board, 2007). The goal is a continuous protected area from Welbedacht in the west to the Gamtoos Estuary in the east, including a Marine Protected Area. This will conserve and protect an entire ecosystem, on which a large portion of the Eastern Cape economy depends (Eastern Cape Parks Board, 2007). 
The development of the Baviaanskloof mega conservation area reflects progress from the proclamation of the state-owned land in the area as a water catchment zone, to the consolidation of a provincial nature reserve system through the acquisition of key properties. This led to the identification of an expanded system that can ensure the protection of the unique biodiversity that occurs there, as well as provide essential sustainable economic development. It is against this background that the author has evaluated the governance options and makes recommendations in his discussion and conclusion.

\section{METHODS}

This article is the result of a research study undertaken by the author based on knowledge gained over a period of 24 years. The direct and indirect observations and experiences include facilitating and participating in several ecotourism workshops convened in the Baviaanskloof Nature Reserve going back as far as 1988. The author also served on the Steering Committee of the Baviaanskloof MegaReserve Project Management Unit (PMU). The author was a team member of the project management team that prepared the Baviaans Responsible Tourism Sector Plan in 2008. More recently the author was a team member on the project management team that was commissioned to prepare a Tourism Development Plan for the Baviaanskloof World Heritage Site zone which is incorporated within the BMR conservation domain. The author's direct involvement in these projects afforded him the opportunity to make observations and to collect relevant unpublished data for his empirical research study.

The study involved a comprehensive literature research referenced at the back of this article, discussions with stakeholders during various public participation processes, extensive travel within the Baviaanskloof mega-reserve region, and interaction with the Eastern Cape Parks \& Tourism Agency (ECPTA). Best practice models and case studies reviewed by the author are referenced at the back of this article.

At this stage of the BMR development a proposed governance model has mainly focused on a protected area cluster (Baviaanskloof Cluster Strategic Management Plan, August 2009). The concept of a Biosphere Reserve as an alternative option has not been discussed with the stakeholders and responsible authorities. This cluster model will be evaluated and compared with a biosphere reserve model. It must be pointed out that the views and recommendations expressed in this article are not necessarily those of the governing body i.e. ECPTA or the stakeholders. It is hoped that this article with stimulate healthy discussion and debate on a biosphere reserve option.

\section{History OF GOVERNANCE}

The Baviaanskloof area has been managed by the Department of Forestry since the early 1920s. The policy then was that of "mountain protection", which was applied in management by the forester stationed at Prince Albert, a small town in the Western Cape Province of South Africa. The first forester in the Baviaanskloof was appointed circa 1930 at Studtis. The Langkloof (Formosa) forestry station was only established in December 1964. The Cockscomb station was established still later in 1974.

The main tasks of Forestry in those years were the creation of firebreaks and control of mountain fires. For this purpose fences were erected. More intensive management has taken place since 1985 with an increased budget and the appointment of more staff for the area. Livestock transgressions were finally curbed by 1990 and the exotic plant problem was tackled with great success through the Working for Water program that is administered by the Gamtoos Irrigation Board.

Large parts of the high-lying areas of the Kouga and Baviaanskloof mountains have always been classified as State land (Crown land) and have never been privately owned. Large areas of mountain land were bought by the State in the early seventies as part of the government's mountain catchment protection policy.

With the building of the Paul Sauer Dam, now known as the Kouga Dam, large areas of land on both sides of the Kouga River were bought out and transferred to the Department of Forestry in 1977 to be managed by them. Since 1986 a further 35,000 ha has been acquired (with the aid of private and government funds) in order to consolidate the core section of the area. On 1 April 1987 the management of the area was transferred from Environment Affairs (Department of Forestry) to Cape 
Nature Conservation as part of the devolution policy of the government. The area has been managed according to the principles of a wilderness area since the early 1980's, even though it was not declared as such. The area was transferred to the Department of Economic Development \& Environmental Affairs (DEDEA) for management during 1994.

In 2002 the Baviaanskloof Mega-Reserve project was initiated and in 2004 the Eastern Cape Parks Board (ECPB) was formed with all DEDEA staff being transferred to the ECPB in 2006. As a means of fulfilling the potential of the area a Baviaanskloof Mega-Reserve Project Management Unit (contracted to DEDEA), was put in place for the progressive planning and implementation of the Baviaanskloof Mega-Reserve. From 2004-2009, the Baviaanskloof Mega-Reserve Project received funding from the Global Environment Facility through the World Bank, with the Wilderness Foundation (a conservation non-profit organisation) contracted as implementing agent.

Since 2010, the mega-reserve project management unit has been run by the Eastern Cape Parks and Tourism Agency (ECPTA). The unit coordinates the Baviaanskloof Liaison Forum, including stakeholders such as DEDEA, community organisations, farmers' organisations, tourism operators and municipalities. The unit also manages projects like the Biodiversity and Citrus Initiative, community beekeeping, small business training and decision-maker wilderness trail projects. The Baviaanskloof Mega-Reserve is also involved with the development of a pilot Biodiversity Stewardship Programme, focusing on the expansion and consolidation of the conservation estate.

In 2010 the Eastern Cape Parks and Tourism Agency Bill, 2010 made provision for the merger of two statutory boards i.e. The Eastern Cape Parks Board and the Eastern Cape Tourism Board.

\subsection{The Act}

"To provide for the establishment of the Eastern Cape Parks and Tourism Agency in order to develop and manage protected areas and to promote and facilitate the development of tourism in the Province and to confer powers, functions and duties upon that Agency; to provide for the management thereof by a Board and the appointment of members thereof; to establish the Eastern Cape Tourism Development Fund and the Eastern Cape Biodiversity Conservation and Development Fund; to provide for the registration of certain persons and amenities involved in tourism; to provide for the collection of levies in respect of registered persons and amenities; to provide for the inspection of premises; to provide for transitional arrangements; and to provide for matters incidental thereto" ((Eastern Cape Parks and Tourism Agency Bill, 2010).

\subsection{Baviaanskloof Mega-Reserve Development and Management Plan}

The Baviaanskloof Mega-Reserve 5-Year Development and Management Plan has a long-term goal of conserving the biodiversity of the Baviaanskloof Mega-Reserve with the delivery of benefits and the full support of local communities, endorsement by government and international recognition. In order to achieve this goal it was important to provide a clear vision, development and management plan to provide the framework in which to operate. The input and support of stakeholders at the initial stage of a project of this magnitude is vital and hence emphasis on this aspect. This project has successfully created the desired framework, which will enable the implementation phase to take place. The project has exceeded most of the purpose indicators with particular success in attracting funding for implementation.

The extensive stakeholder process required was however underestimated but the time extension allowed for the completion of this aspect. With the change in status to a World Heritage Site as well as the establishment of a new management authority (Eastern Cape Parks \& Tourism Agency) further attention will need to be given to securing satisfactory institutional arrangements, supporting effective management as well as clarifying the status of the Protected Area. The Baviaanskloof Mega-Reserve Project is firmly established within the broader conservation community and most importantly amongst local stakeholders as an ambitious project that can produce significant gains for biodiversity conservation as well as the regional economy.

The Project Purpose is to establish an effective and sustainable vision and 5-year development and management plan for the Baviaanskloof Mega-Reserve area that is accepted by the stakeholders. The vision and plan includes: plans for expanding the protected areas, plans for sustainable community utilization of biodiversity which benefits local communities and biodiversity, and plans to enhance co- 
operative governance, promote community participation and to support institutional capacity of management. There were some unexpected impacts, positive and negative, which are indicated below:

\subsection{Positive Impacts}

- Extended stakeholder process resulted in higher levels of buy in and support than expected including landowners and local communities.

- The Baviaanskloof as one of three Mega Reserves is providing examples (negative and positive) with specific reference to process from which other initiatives can learn.

- Improved levels of cooperation across institutional boundaries particularly as a result of involvement in forums such as the Protected Areas forum and other Cape Action for People and the Environment (CAPE) driven initiatives.

- Improved opportunities for funding for implementation.

\subsection{Negative Impacts}

The stakeholder process opened up sensitive debates around traditional leaders and support base with political connotations that will need to be addressed. This could also be seen as a means to resolve an issue that could make a positive contribution to the greater project.

\subsection{Lessons Learned During the Various Phases of the Project}

- Stakeholder processes need specific attention and skills. They also need to be implemented at a pace that is constructive and supportive or else they can cause increased tension and levels of misunderstanding amongst stakeholders;

- Different styles of engagement are appropriate for different stakeholder groups and individuals;

- Make use of local champions as a means to carry positive messages to communities;

- Make use of people with local knowledge to advise on process and approach;

- A plan remains a plan, the challenges lie in effective implementation.

\subsubsection{Aspects of the project design that contributed to its success/failure}

- The initial stakeholder process was insufficient but extension of the project period and reevaluation enabled a potential shortcoming in the final product to be corrected.

\subsubsection{Aspects of the project execution that contributed to its success/failure}

- Extensive use of a wide spectrum of stakeholders resulted in constructive critical input into the final product

- Establishment of working group task teams or sub-committees as a means to focus stakeholder input is clearly a good approach. However, it is important to note that getting theses bodies to function productively is often more difficult than establishing them, and can be very time consuming.

- Ability of the PMU to adapt their approach resulted in a successful completion of the project within its objectives.

The measurement of planned versus actual performance is tabled below:

\begin{tabular}{|l|l|}
\hline \multicolumn{2}{|c|}{ PLANNED VERSUS ACTUAL PERFORMANCE } \\
\hline \multicolumn{1}{|c|}{ Indicators } & \multicolumn{1}{c|}{ Actual at completion } \\
\hline $\begin{array}{l}\text { Effective management of the BMR by } \\
\text { the designated management agency }\end{array}$ & $\begin{array}{l}\text { The magnitude of the management responsibility is enormous } \\
\text { and in fact increasing as the area expands. The previous } \\
\text { management was less than effective but this will be addressed } \\
\text { as a critical area in the GEF project. }\end{array}$ \\
\hline $\begin{array}{l}\text { Stakeholders and local communities } \\
\text { were effectively involved in decision- } \\
\text { making and management of the BMR }\end{array}$ & $\begin{array}{l}\text { Various meetings and workshops were held over an 18-month } \\
\text { period (Feb 2003-August 2004) with the local communities, } \\
\text { Landowners \& Municipalities to discuss the vision of the } \\
\text { BMRP. The key performance areas as well as broad principles } \\
\text { regarding possible projects of the BMRP were discussed and } \\
\text { agreed on. A Stakeholder Working Group was established to } \\
\text { assist with guidelines in terms of Project implementation. }\end{array}$ \\
\hline
\end{tabular}




\begin{tabular}{|l|l|}
\hline $\begin{array}{l}\text { Partnerships between civil society and } \\
\text { BMR management was secured }\end{array}$ & Several completed and ongoing. \\
\hline $\begin{array}{l}\text { Objectives and spatial extent of the } \\
\text { BMR were incorporated into the } \\
\text { statutory approved Integrated } \\
\begin{array}{l}\text { Development Plans of the Cacadu } \\
\text { municipalities by June 2005 }\end{array}\end{array}$ & $\begin{array}{l}\text { Some BMR plans were included in the local municipal } \\
\text { Integrated Development Plans (IDP's) (4 local, 2 district, } 1 \\
\text { metro municipality). Interactions regarding inclusion of plans } \\
\text { into the Cacadu District Municipality (DM) IDP was discussed } \\
\text { with the Executive Mayor, Municipal Manager \& Mayoral } \\
\text { Committee and there was general agreement that once the plans } \\
\text { are included in the local municipal IDP's, they will be } \\
\text { incorporated in the DM IDP. }\end{array}$ \\
\hline $\begin{array}{l}\text { Boundaries of the BMR effectively } \\
\text { contribute to corridor conservation of } \\
\text { CFR biodiversity }\end{array}$ & $\begin{array}{l}\text { Significant contribution is envisaged and the plans reflect this. } \\
\text { As the project is implemented the contribution will be realized. }\end{array}$ \\
\hline $\begin{array}{l}\text { The Project Management Unit was } \\
\text { established and completed its } \\
\text { operational function }\end{array}$ & $\begin{array}{l}\text { A Landowner Liaison Manager and a Special Projects } \\
\text { Coordinator were employed to complement the work of the } \\
\text { already established PMU. }\end{array}$ \\
\hline
\end{tabular}

(Source: Wilderness Foundation Final Project Completion Report)

\subsection{Achievement of Project Purpose}

The project has been widely embraced at a senior political level both municipal and provincial. The project was successful at a number of levels. The setting up of a representative Steering Committee, provided stakeholders with a platform for formal engagement and the stability of the BSC will be particularly beneficial during the challenges of implementation. The establishment of relationships with civil society groups, NGO's, academic institutions and municipalities as a result of the stakeholder component will prove invaluable as the Mega-Reserve Project develops.

\section{Baviaanskloof Cluster Strategic Management Plan 2009}

\subsection{Contextual Framework}

The Baviaanskloof Reserve Cluster is made up 3 nature reserves (currently in the process of being formally proclaimed as provincial nature reserves) i.e. the Baviaanskloof Nature Reserve, the Formosa Nature Reserve and the Groendal Nature Reserve, situated in the western region of the Eastern Cape Province, extending from Uitenhage near Port Elizabeth to Willowmore on the Western Cape Boundary (see Map overleaf). The Cluster covers most of the Kouga and Baviaanskloof Mountain Ranges, part of the Tsitsikamma Mountains in the South, and part of the Grootwinterhoek and Elandsrivier Mountains to the East. The Cluster is situated between the arid Steytlerville Karoo and the mesic southern Cape coast. The bulk of the Cluster falls within the eastern part of the Cape Floristic Region (Fynbos biome). The northern areas of the Cluster fall within the Nama-karoo biome while the eastern areas mostly fall within the Subtropical Thicket biome. The Forest biome is represented in the narrow river valleys and the Grassland biome is represented on the plateaus of the Old African Land Surface in the Kouga and Baviaanskloof Ranges (Baviaanskloof Cluster Strategic Management Plan 2009). These nature reserves comprise a number of management sections and subsections as indicated on the next page.

These nature reserves totaling an area of 299,078 ha comprise several management sections and subsections (refer to Map on the next page) as follows:

- The Baviaanskloof Nature Reserve (211,476 ha) consists of three contiguous sections; namely the Western Section, Cockscomb Section and Kouga Section. The Western Section includes the discontiguous Welbedacht sub-section.

- Groendal Nature Reserve (45,428 ha) consists of two sections; namely the main Kwa-Zunga Section in the Grootwinterhoek Mountains and the separate Stinkhoutberg Section situated north of Patensie. The Kwa-Zunga Sections includes a small separate sub-section, Mierhoopplaat.

- Formosa Nature Reserve $(45,173)$ is not divided into Sections but has a small sub-section, Niekerksbergs, which lies 14 Kilometres to the west of the Cluster. Formosa nature Reserve is also responsible for the Kouga Section of the Baviaanskloof Nature Reserve. 


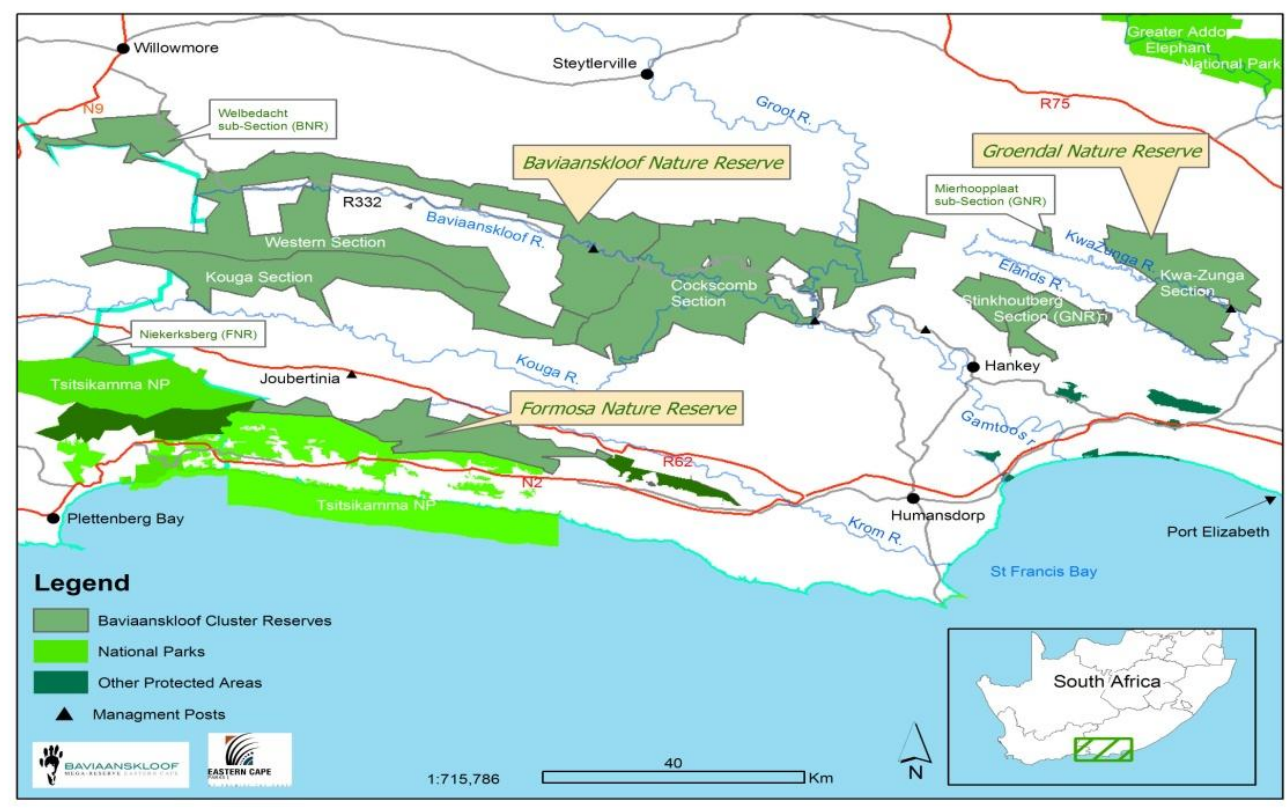

(Source: Baviaanskloof Cluster Strategic Management Plan, 2009)

The focus of this Strategic Management Plan (SMP) is to develop a common, medium term (5-year) operational framework for the Baviaanskloof Reserve Cluster (BRC) that strategically directs and coordinates the prioritized allocation of resources and capacity to the three Clusters in order to achieve a common set of goals and objectives. The Baviaanskloof Nature Reserve was declared a World Heritage Site as part of the Cape Floristic Region Serial Nomination in June 2004. The basis of the WHS status is the outstanding floristic diversity and endemism of the CFR. The WHS status places the Baviaanskloof Nature Reserve in a special category in terms of the Protected Areas Act, and the implications for management have been investigated by the ECPTA, CAPE and DEAT. ECPTA was appointed authority of the World Heritage Site in 2010.

The Baviaanskloof WHS is managed by the Operations Directorate of the Eastern Cape Parks \& Tourism Agency (ECPTA). The Cluster is located within the Western Region of the Directorate, and falls under the oversight of the Regional Manager: West. The Cluster is under the management responsibility of the Regional Manager: West (based in Port Elizabeth), and four Reserve Managers. The operational management of the Cluster is directly supported by the ECPTA head office support services such as finance, administration, scientific services.

The Vision is to effectively manage and develop the Baviaanskloof WHS to ensure that the biodiversity, ecosystems and large scale ecological and evolutionary processes are conserved while maintaining its World Heritage Site status and Wilderness character. Each Key Result Area (KRA) in the SMP is directed by a number of objectives. Each objective will be achieved through a set of activities and will result in a number of deliverables within a defined time frame. The prioritized achievement of the objectives will be monitored using performance indicators within a set time frame. These objectives, activities, time frames performance indicators, and deliverables are presented in a $\log$ frame format for each KRA.

\subsection{Stakeholder Involvement and Partnerships}

The Strategic Goal of the ECPTA Strategic Plan relating to stakeholder involvement and partnerships is Linking People and Parks. The strategic objective is 'Transforming the relationship between parks and neighbors from 'exclusion' to 'involvement' by 2008'. The relative interventions to achieve this goal and objectives are:

- Making it possible for communities and stakeholders to participate in management processes;

- Building an image that brands the organization as one that conserves biodiversity through involvement of people.

The medium-term focus for the cooperative governance component of this KRA is the improvement of relationships with local, provincial and national public bodies and institutions. The medium-term 
strategic focus for the communication component of this KRA is the development and maintenance of, and involvement in, bilateral forums and other interest groups including the involvement in forums with interest groups and the appointment of dedicated community liaison staff.

The medium-term strategic focus for the benefit sharing component of this KRA is to:

- Ensure the successful implementation of existing CEFP funded community

- Facilitate the development of further projects delivering benefits to local communities

- Identification of conservation related employment opportunities for members of local communities

- Identification of opportunities for the involvement of local communities in tourism related activities

- Testing the feasibility of applying community levies to reserve transactions

The medium-term focus for the commercialization component of this KRA is to explore the feasibility of offering concessions for some of the tourism related opportunities in the Reserve.

\subsection{Tourism Development}

To achieve the vision tourism was identified as a lead sector that could generate income, allow for affordable access, stimulate economic development, encourage partnerships and leverage biodiversity in adjacent areas (Baviaanskloof Mega-Reserve Financial Feasibility Study, Richard Davies).

\subsection{Products and Activities}

Tourism activities include fishing, hiking, mountain biking, swimming, picnicking, bird watching and game viewing. There is one formal 4 x 4 Route, the Osseberg route which is a circular route for which a permit and access key can be obtained at the Komdomo entrance (booking required through central reservations). Fishermen need a permit issued by the ECPTA for fishing in the various rivers (as well as an official Freshwater Fishing Permit). This still has to be formalized through an agreement with ECPTA. Alien fish (Bass, Barbel and Tilapia) can however be removed with no restrictions.

Interest in wildlife is growing considerably, in particular as its exposure in the international media increases. As with bird watching, the National Geographic television channels such as Nat Geo Wild, and other renowned television channels such as Animal Planet, have generated increased interest amongst consumers. Mountain biking in this area is proving to be an extremely popular event both with experienced bikers and also with family and social groups. There is still considerable potential for growth within this market, and it is expected to expand by between $8 \%$ and $10 \%$ per annum over the next decade.

The BMR domain provides a perfect classroom for nature based learning experiences. The tourism potential of the BMR is significant based on the beauty and great diversity of its terrain and the malaria free climate.

The sustainable future of the BMR will depend on how effectively the natural environment is managed. This should include actions such as:

- Recognition that the natural diversity and beauty of the BMR is its draw card.

- Protection of the terrain by expanding the protected areas.

- Upgrading the quality of tourist accommodation and facilities by establishing new facilities within an overall policy of land zoning and protection.

- Investing in roads to improve access for tourists.

- Supporting cultural tourism initiatives developed by communities to increase rural and urban incomes and employment from tourism.

\section{DisCUSSION}

\subsection{Management Effectiveness of South Africa's Protected Areas Study 2010}

There are many reports that have been published on protected areas governance of which a few have been listed in the references included in this article. The report on the effectiveness of South Africa's 
protected areas, commissioned by the Department of Environmental Affairs (DEA) in 2010 assessed two hundred and thirty protected using the METT-SA (Version 1) during this study. This equates to $78 \%$ of the total number of protected areas on the Register of Protected Areas managed by the state at national and provincial level in South Africa. Therefore South Africa has exceeded the recommendations set out in Goal 4.2 of the Convention on Biological Diversity's Program of Work for Protected Areas, in which Parties are to implement management effectiveness evaluations of at least $30 \%$ of their protected areas by 2010 .

The Management Effectiveness Tracking Tool (METT) has been used in a number of countries to evaluate the management effectiveness of their protected areas. The adaptation of this tool to the METT-SA (Version 1) for use in South Africa made it more relevant to the country's situation, and relatively easy to apply.

One of its shortcomings is that it does not assess the value of the protected area to the system. The assessment of pressures and threats was added part of the way through the assessment program. This will be remedied in the follow up studies. In addition it is not designed to provide comparisons between protected areas or between management authorities. The method of application was one of self-evaluation by the management authority for their protected areas. Some of these authorities provided a rigorous peer review system in their assessments while others did not. Some of the authorities involved a wide range of staff responsible for different aspects of the management of their protected areas, while others restricted the involvement to their senior management. Therefore any comparison of scores between protected areas and or between management authorities is only indicative at best and irrelevant at worst.

However the DEA study provides a baseline for each protected area managed by its management authority against which the authority can measure its progress in improving (or otherwise) the management of the protected area. The study has helped identify problems at the specific protected area which need to be addressed in order to improve that management over the next few years. Some of the problems will be relatively simple to improve, while others may be complex, difficult and demand increased resources before improvement can be made.

The study recommended that a review of the value of each protected area should be undertaken. Those areas which have no value to the protected area estate should lose their protected area status and the resources used for their management should be redeployed to those that do and are in need of additional resources. Each management authority should set a short term goal for the improvement of the management of their protected areas, based on addressing the problems identified in this study. It is recommended that a minimum score using the METT-SA (Version1) assessment tool should be set at $67 \%$. Where possible, following the Ezemvelo-KZN-Wildlife example (Carbutt and Goodman 2010), a minimum effective score should be set at $77 \%$.

Having set a target, the management authorities should work effectively towards improving the management of their protected areas. An annual, internal review on the progress towards meeting the targets should be undertaken. Where possible the peer review system should be employed, at least within the management authority. Finally, a similar national assessment should be done in 2014 to check progress. That assessment should attempt to obviate the problems identified in this 2010 study.

It is worth noting that the DEA study did not include an assessment of biosphere reserves in South Africa. In 2011 there were 580 sites in over 118 countries listed on the World Network on Biosphere Reserves. South Africa currently boasts six Biosphere Reserves namely: Kogelberg (1998), Cape West Coast (2000), Kruger to Canyons (2001), Waterberg (2001), Cape Winelands (2007), and Vhembe (2009). Certainly the BMR has all the characteristics of a UNESCO registered biosphere reserve with the added value of containing a UNESCO world heritage site.

\subsection{Third Generation Protected Areas}

The concept of third generation protected areas developed by Dr Michael Jungmeier takes into consideration the change in paradigms in nature conservation in general, and in protected areas in particular. This change has provoked alternatives to the traditional top-down, sovereign and prohibitive concepts of protected areas of the first generation. The second generation, "landscapes of hope" focuses on mediating between different interests, in particular the discrepancies between conservation and development. This ushered in a new understanding and practical solutions. 
However, the new developments seem to go beyond this line, constituting already a third generation of protected areas. The elements that may be most distinctive are the steering mechanisms deriving from the principles of public administration to management and finally to governance, upgrading the people concerned to become stakeholders and then to owners.

Screening the different types and categories of protected areas, internationally some 20 IUCN categories, such as world heritage sites, biosphere reserves, Ramsar-sites, etc, and the concept of biosphere reserves seems to be prototypes for a third generation of protected areas. The management of protected areas has recently emerged as a new scientific discipline. To date, there is a lack of systematic and theoretical background. A study by Jungmeier (2011) explored this vast field by combining different disciplines in an inter-disciplinary and trans-disciplinary approach. Taking two existing Austrian biosphere reserves (Großes Walsertal BR, Wienerwald BR) and one national park (Nockberge NP, BR planned) as typical examples, Jungmeier and his team analyzed basic management principles in terms of intervention, participation, regional governance and change management. The broad base and special methodological approach showed the complexity of planning and managing a biosphere reserve (Jungmeier, 2011).

How local stakeholders perceive the process of development very often differs from what the planning regime was meant to do. The overwhelming importance of regional history, the power of established structures and social components (trust, enthusiasm etc.) can turn planning intentions into an unpredictable direction. Only a precise and focused strategic mix of process components can ensure a successful process. What constitutes an effective mix differs from region to region and must be defined individually. It also became clear that different phases of BR development need specific management approaches as intervention takes place in a typical order. Once again, proper participation proved crucial for the success of a BR (Jungmeier, 2011).

Biosphere reserves usually consist of a core area i.e. a previously designated park, wilderness area, wildlife refuge, or scientific research area. In some countries, biosphere reserves are often "created from scratch" rather than being overlaid on an existing protected area. Today, all protected areas including the most strictly protected ones, such as national parks and designated wilderness areas, are based on a principal of cooperation.

\subsection{Benefits of Biosphere Reserves}

- The biosphere reserve concept can be used as a framework to guide and reinforce projects to enhance people's livelihoods and ensure environmental sustainability. UNESCO recognition can serve to highlight and reward such individual efforts.

- Designation of a site as a biosphere reserve can raise awareness among local people, citizens, and government authorities on environmental and development issues. It can help attract additional funding from different sources.

- At the national level, biosphere reserves can serve as pilot sites or "learning places" to explore and demonstrate approaches to conservation and sustainable development, providing lessons which can be applied elsewhere.

\section{Structure of a model biosphere reserve.}
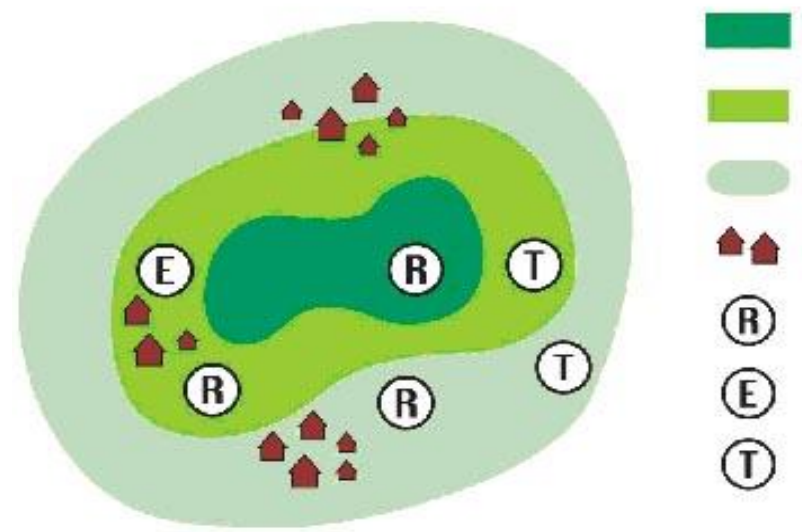

Core Area

Buffer Area

Transition Area

Human Settlement

Research

Education / Training

Tourism / Recreation 


\subsection{Biosphere Legislation}

In most countries it is not been found necessary to enact special national legislation for biosphere reserves; instead, existing legal frameworks for nature protection and land/water management are used. That being said, today an increasing number of countries are passing national biosphere reserve legislation in order to make their legal status perfectly clear.

\subsection{Criteria for Biosphere Reserves}

To be considered as a biosphere reserve, an area must at minimum meet the legal protection requirements for a core area. Ideally, in addition the area would have an identified and viable buffer zone and transition zone, but, as noted above, in practice these are often not present.

Basic requirements include:

- each unit be a unique resource representative of a larger region with a legally protected core area that is shielded from unbridled development

- have a history of scientific study and be active in ecological research and monitoring

- be active in the education and training of resource management professionals

- be dedicated to consciousness raising among the general public a gathering place for regional dialogue about current environmental and economic growth issues.

\subsection{Selecting a Site}

Parties interested in establishing a biosphere reserve work through their country's national MAB (Man and the Biosphere Reserves) committee to nominate an area using a detailed nomination form. The nomination is then forwarded to the MAB Council where it is considered at one of its regular meetings. If the nomination is approved, then the designation is confirmed and the area begins to operate as a biosphere reserve. Concerned with problems at the interface of scientific, environmental, societal and development issues, MAB combines natural and social sciences, economics and education to improve human livelihoods and safeguard natural ecosystems, thus promoting innovative approaches to economic development that is socially and culturally appropriate and environmentally sustainable. UNESCO oversees biosphere reserves only to the extent of making sure that they meet the minimum criteria outlined above. As called for in the Statutory Framework for Biosphere Reserves, every 10 years the MAB reviews each biosphere reserve in the network to make sure each is still meeting the criteria.

This is done by reviewing reports submitted by the managing agency(ies) or organization(s). If the MAB Council finds that a particular biosphere reserve no longers meets the minimum criteria, it will work with the managing agency to resolve the problem. If that is not successful, then the MAB Council can cancel the biosphere reserve designation and the area will no longer be referred to as such. To date, this has never happened, though agencies in several countries have voluntarily withdrawn non-functional sites with the agreement of the MAB Council.

\subsection{The Issue of Economic Impacts}

Other legitimate concerns with biosphere reserves are what effect the designation might have on property values and on the willingness of businesses to locate within the buffer and transition zones, and whether the biosphere reserve will change patterns of tourism in the area. Anecdotal evidence suggests that property values in the immediate vicinity of conventional protected areas, such as national parks, often increase because of the amenity value people ascribe to living near assets such as parks. If one looks at the areas around national parks that are also biosphere reserves, places in the US such as Everglades, Glacier, Great Smoky Mountains, Grand Canyon, and so on, there does not appear to have been any reduction in the desirability or value of property after parks became biosphere reserves.

Nor is there any evidence to suggest that businesses will be less likely to locate within the buffer or transition zones of a biosphere reserve. While it is conceivable that certain business owners may not want to locate within a biosphere reserve because of their negative perceptions of the designation, it is equally conceivable that owners of other businesses might be attracted to locate in the biosphere reserve because they want to be part of a community that encourages environmentally sensitive, 
sustainable development. More likely than either, though, is that the biosphere reserve designation will have no impact on business location decision-making.

Tourism in biosphere reserves is almost exclusively associated with visitation to their core zones which are already-existing protected areas. No evidence has been found to show that creation of a biosphere reserve has changed tourism patterns in the surrounding region. All in all, a biosphere reserve designation probably has a negligible effect, positively or negatively, on tourism.

However, one function of a fully functioning biosphere reserve i.e. the conservation of the unique environment and culture of the surrounding region has the potential to make an indirect, but considerable, positive contribution to the regional economy. Ecotourism and heritage tourism are two of the fastest-growing segments of the domestic and global tourism industry. To the extent that biosphere reserves can help preserve and sustainably develop the distinctive features of the region, they are a powerful tool to help build a viable and stable economy for local communities.

\section{CONCLUSiON}

\subsection{Cluster versus Biosphere Mega-Reserve}

The Baviaanskloof Cluster Strategic Management Plan 2009 refers to the Baviaanskloof Reserve Cluster (BRC). Universally a cluster is considered a collaborative economic development process or mechanism to develop the comparative or competitive advantages of stakeholders who have a vested interest in a defined geographical area e.g. conservation estate. The business philosophy which underpins a cluster is the spirit of cooperation and competition (coopetition). The author suggests that a Biosphere Mega-Reserve is a better and more appropriate mechanism for encouraging cooperation within the BMR conservation domain. A biosphere reserve is a special kind of protected area that differs from a national park, wilderness area, national forest, or wildlife refuge in having three very different, but equal, aims: conservation of genetic resources, species, and ecosystems; scientific research and monitoring; and promoting sustainable development in communities of the surrounding region. All three of these aims are equally important in a biosphere reserve.

\subsection{From Constituents to Stakeholders}

Whether serving, advocating for, or organizing constituents, an organization can build constituents into stakeholders and expand their role in and ownership of the organization's success. Stakeholders are the people who care about an organization and consider it their own. Some obvious stakeholders include donors, board members, staff, and close allies.

First and foremost, engaging constituents as stakeholders keeps organizations responsive to community needs. Because of their direct experiences, constituents often have unique views of how social service programs, community development projects, and public policies play out in their lives. When constituents participate in an organization, whether that organization exists to meet their immediate needs or to build their political power, they help ensure that the solutions it puts forward are relevant and effective.

Community impact includes aligning new program development with the organization's mission. It also includes the ability to meet needs in a service organization, build the power of grassroots leaders in an organizing group, or enable constituents to publicly represent the organization and its issues. Due to the past political system of separate development in South Africa most host communities regarded themselves as constituents and not as stakeholders. Communities living on the peripheral of protected areas worked for the organization but never ever felt any sense of belonging or ownership.

Whether an organization seeks to better educate and involve constituents or develop them as organizational or community leaders, possible approaches include the following:

Start strong: When you form an organization or a new program begins, engage constituents in the planning, development, and direction of the new effort. This establishes them as stakeholders from the beginning and creates a sustainable base of support.

Amplify their voice: Constituents understand the problems they experience in direct and concrete ways. This experience has significant credibility when addressing outside audiences, particularly policymakers or government officials. Work with constituents so they can provide their own expertise, tell their stories in compelling ways, and frame needed solutions. 
Support, support, support: Use education, training, and participation in real work to create the awareness of a problem and build constituents' skills and capacity to take on ever greater levels of stakeholder responsibility.

Make it real: Routine manual work is necessary to make an effort successful, but ensure that constituents have opportunities to do something meaningful within the organization and/or as its representatives.

Exchange services for effort: Where appropriate, consider requiring constituents receiving services from an organization to give back time and effort in support of the group's policy efforts and infrastructure.

Meet people where they are: Especially when engaging organizations (but also individuals), don't push your ideas onto their agenda. Rather listen for where they are, build a relationship, and find ways of integrating your agenda into theirs.

Step back: If you want others to take up their leadership, it is often important for organizational or traditional leaders to create space and real opportunities for constituents to step up and take on responsibility.

Relationships matter: Creating ways for constituents to connect, share their stories, and work together can enable them to overcome fears and other obstacles and become real stakeholders.

Win early: Being able to demonstrate even small policy, administrative, or other wins to your constituents builds needed momentum and can sustain longer-term efforts towards even bigger successes.

Connect around deeply held cultural or spiritual values: Identifying a common set of ideals or cultural/spiritual values can be a powerful foundation for framing an effort and engaging constituents in a sustainable way.

These approaches, of course, are just some of the strategies that can be used to help constituents become stakeholders and help community-based organizations build their effectiveness and maintain a relevant and vibrant sense of mission. No matter how one approaches it, this process, while labor intensive and challenging at times, is critical to sustaining efforts that enrich the lives of all citizens; and ultimately strengthen neighborhoods, towns, cities, protected areas, and the country as a whole.

\subsection{Biosphere Reserves facilitate the transition from Constituents to Stakeholders}

By design, there is no single model for governing biosphere reserves, but there are two common underlying principles: the management system of a biosphere reserve needs to be open, not closed, to community concerns; and it needs to be adaptible to changes in local circumstances. Biosphere reserves are meant to be places where communities can work in concert with the area's land-managing agencies, local governments, schools, and other institutions to design responses to external political, economic, and social pressures that affect the ecological and cultural values of the area. Each biosphere reserve has its own system of governance to ensure that it meets its functions and objectives. Often it is found useful to set up a committee or board that coordinates all biosphere reserve's activities. Usually a coordinator is named as the contact person for all matters dealing with the biosphere reserve. In this respect Protected Area managers should develop the relevant skills to become excellent coordinators.

In the author's opinion the diverse character of the Baviaanskloof Mega-Reserve is ideally suited for consideration as a Biosphere Reserve. It could encourage farmers, conservationists, local communities, businesses, accommodation providers, tour operators, local municipalties and all other stakeholders to coexist in harmony while at the same time supporting a conservation ethic that will ensure the long-term sustainabily of the area.

\section{RECOMMENDATIONS}

The author strongly recommends that the BMR should be assessed to determine if the mega-reserve has made the transition from a second-generation to a third-generation PA using Jungmeier's 'finger print' assessment model. A study by Jungmeier (2011) explored this vast field by combining different disciplines in an inter-disciplinary and trans-disciplinary approach. Taking two existing Austrian biosphere reserves (Großes Walsertal BR, Wienerwald BR) and one national park (Nockberge NP, 
BR planned) as typical examples, Jungmeier and his team analyzed basic management principles in terms of intervention, participation, regional governance and change management. The broad base and special methodological approach showed the complexity of planning and managing a biosphere reserve (Jungmeier, 2011). A 'finger print' assessment would provide a framework for the most appropriate governance model for the BMR.

\section{ACKNOWLEDGEMENTS}

The author wishes to acknowledge the various authors of research studies, tourism development plans, conservation development plans, concept documents, feasibility studies, and other relevant documents that have contributed to various stages of development towards the establishment of the Baviaanskloof Mega-Reserve and potential Biosphere Reserve. Many of these valuable documents are unpublished. The author also wishes to thank Wayne Erlank, Manager: Regional, Routes and Reserves (West), Eastern Cape Parks \& Tourism Agency (ECPTA), for his cooperation and support of this empirical research study.

\section{REFERENCES}

[1] Boshoff, A., Cowling. R., Kerley, G., 2000. The Baviaanskloof Conservation Area: A Conservation and Tourism Development Priority, Terrestrial Ecology Research Unit, University of Port Elizabeth, Report No. 27, April 2000, ISBN: 0-86988-754-8

[2] Boshoff, A., 2005. The Baviaanskloof Mega Reserve Concept Document, Terrestrial Ecology Research Unit, Nelson Mandela Metropolitan University, Terrestrial Ecology Unit, Report No. 52 May 2005, ISBN: 0-86988-839-0

[3] Baviaanskloof World Heritage Site Tourism Development Plan December 2012, prepared for the Eastern Cape Parks \& Tourism Agency and funded by DBSA

[4] Baviaanskloof Tourism Development Plan Model, Robford Tourism, 2007

[5] Baviaanskloof Cluster Strategic Management Plan, 2009

[6] Baviaans Responsible Tourism Sector Plan 2008

[7] Carbutt, C. \& Goodman, P.S., 2010. Assessing the management effectiveness of state owned land based protected areas in KwaZul-Natal. Unpublished report, Ezemvelo KZN Wildlife. Convention of Biological Diversity, (2004).

[8] Dudley, N., Hurd, J., and Belkinov, A., 2005. Towards and effective protected areas network in Africa. WWF Internaltional, Gland, Switzerland.

[9] Dudley, N., Belokorun, A., Higgings-Zogib, L., Hockings, M., Stolton, S., Burgess, N., (2007), Tracking progress in managing protected areas around the world: An analysis of two applications of the Management Effectiveness Tracking Tool developed by the WWF and the World Bank, World Wildlife Fund, International.

[10] Davies, R., 2008, Baviaanskloof Mega Reserve Financial Feasibility Study

[11] Eastern Cape Parks and Tourism Agency Bill, 2010.

[12] Ervin, J., (2007). Assessing Protected Area Management Effectiveness: A quick guide for practitioners. Quick Guide Series ed, J. Ervin. Arlington, VA: The Nature Conservancy.

[13] Hockings, M., Stolton, S., Leverington, F., Dudley, N. and Courrau, J. (2006). Evaluating Effectiveness: A framework for assessing management effectiveness of protected areas. 2nd edition. IUCN, Gland, Switzerland and Cambridge, UK.

[14] IUCN, 2002, World Heritage Manuals, Managing Tourism World Heritage Sites: A practical Manual for World Heritage Site Managers.

[15] IUCN, 2001, Protected Areas Program, Parks Vol. 11 No. 1, Biosphere Reserves.

[16] IUCN, 2012, Governance of Protected Areas: From Understanding to Action, Draft for Comments.

[17] IUCN, 2012, Managing Natural World Heritage Resource Manual

[18] IUCN, 2011, Biosphere Reserves, Volume 11, No. 1

[19] IUCN Guidelines of the Best Practice Protected Area Guidelines series. The current Series Editor is Prof. Peter Valentine. Publications in the series include the following:

[20] National System Planning for Protected Areas. No. 1. Adrian G. Davey, 1998, x + 71pp.

[21] Economic Values of Protected Areas: Guidelines for Protected Area Managers. No. 2.

[22] Task Force on Economic Benefits of Protected Areas of the World Commission on Protected Areas (WCPA) of IUCN, in collaboration with the Economics Service Unit of IUCN, 1998, xii + 52pp

[23] Guidelines for Marine Protected Areas. No. 3. Graeme Kelleher, 1999, xxiv + 107pp. 
[24] Indigenous and Traditional Peoples and Protected Areas: Principles, Guidelines and Case Studies. No. 4. Javier Beltrán, (Ed.), IUCN, Gland, Switzerland and Cambridge, UK and WWF International, Gland, Switzerland, 2000, xi + 133pp.

[25] Financing Protected Areas: Guidelines for Protected Area Managers. No.5. Financing Protected Areas Task Force of the World Commission on Protected Areas (WCPA) of IUCN, in collaboration with the Economics Unit of IUCN, 2000, viii + 58pp.

[26] Evaluating Effectiveness: A Framework for Assessing the Management of Protected Areas. No. 6. Marc Hockings, Sue Stolton and Nigel Dudley, 2000, x + 121pp

[27] Transboundary Protected Areas for Peace and Co-operation. No. 7. Trevor Sandwith, Clare Shine, Lawrence Hamilton and David Sheppard, 2001, xi + 111pp. Reprinted in 2003.

[28] Sustainable Tourism in Protected Areas: Guidelines for Planning and Management. No.8. Paul F. J. Eagles, Stephen F. McCool and Christopher D. Haynes, 2002, xv + 183pp

[29] Guidelines for Management Planning of Protected Areas. No.10. Lee Thomas and Julie Middleton, 2003, ix $+79 \mathrm{pp}$

[30] Indigenous and Local Communities and Protected Areas: Towards Equity and Enhanced Conservation. No. 11. Grazia Borrini-Feyerabend, Ashish Kothari and Gonzalo Oviedo, 2004, xvii + 112pp.

[31] Sustainable Financing of Protected Areas: A global review of challenges and options. No.13. Lucy Emerton, Joshua Bishop and Lee Thomas, 2006, x + 97pp

[32] Jacobson, C., Carter, R.W., and Hockings, M.T., (undated). The status of protected area management evaluation in Australia and implications for its future, Unpublished Paper

[33] Jungmeier, M., 2011, In Transit towards a Third Generation of Protected Areas? Analysis of Disciplines, Forming Principles and Fields of Activities by Example of Recent Projects in Protected Areas in Austria, International Journal of Sustainable Society, Special Issue: Contribution of Protected Areas to Sustainability.

[34] Jungmeier, M., Getzner, M., Lange, S., (2010). People, Parks and Money - Stakeholder Involvement and Regional Development: a Manual for Protected Areas, Klangenfurt University, ISBN 978-3-7084-0413-4, 2010.

[35] Jungmeier, M., et al. 2011. Biosphere reserves as a long-term intervention in a region - strategies, processes, topics and principles of different participative planning and management regimes of biosphere reserves, Research eco.mont - Volume 3, Number 1, June 2011, ISSN 2073-106X print version ISSN 2073-1558 online version: http://epub.oeaw.ac.at/eco.mont

[36] Leverington, F., Hockings, M., and Costa, K.L., (2008) Management effectiveness evaluation in protected areas: Report for the project 'Global study into management effectiveness evaluation of protected areas', The University of Queensland, Gatton, IUCN WCPA, TNC, WWF, AUSTRALIA

[37] Management effectiveness of South Africa's protected areas, Langhammer, P.F., Bakarr, M.I., Bennun, L.A, Brooks, T.M., Clay, R.P., Darwall, W., De Silva, N., Edgar, G.J.,Eken, G., Fishpool, L.D.C., Fonseca, G.A.B. da, Foster, M.N., Knox, D.H., Matiku, P., Radford, E.A., Rodrigues, A.S.L., Salama, P., Sechrest, W., and Tordoff, A.W., (2007)

[38] Minieri, J., Dodge, J., Foldy, E., et al, From Constituents to Stakeholders - Community-Based approaches to building Organizational Ownership and Providing Opportunities to Lead, Research Centre for Leadership in Action, Robert F. Wagner Graduate School of Public Service, New York (undated).

[39] Nordin, S., 2003, Tourism Clustering \& Innovation: Paths to Economic Growth \& Development, European Tourism Research Unit, ISBN 91-970001-9-1-2003

[40] Smith, R. 2001. A preliminary survey of Rock Art and other San sites in and around the Baviaanskloof Wilderness Complex, September 2001

[41] UNESCO, 2008, Planning for World Heritage Sites: A Toolkit

[42] UNESCO "Man and Biosphere Programme" MAB FAQs

[43] UNESCO "Man and Biosphere Programme” MAB Fact Sheet

[44] WCPA Management Guidelines for IUCN Category V Protected Areas/Protected Landscapes/Seascapes

Citation: Peter B. Myles. "Towards a Governance Model for a Biosphere Mega Reserve in South Africa". International Journal of Research in Tourism and Hospitality (IJRTH), vol 4, no. 2, 2018, pp. 1-17. doi:http://dx.doi.org/10.20431/2455-0043.0402001.

Copyright: (C) 2018 Authors. This is an open-access article distributed under the terms of the Creative Commons Attribution License, which permits unrestricted use, distribution, and reproduction in any medium, provided the original author and source are credited. 